\title{
Resenhas
}

\section{História do ensino de História no Brasil: uma retomada plural ${ }^{*}$}

Helenice Aparecida Bastos Rocha*

Thais Nivia de Lima e Fonseca, História \& Ensino de História, Belo Horizonte, Autêntica, 2003, 120 p.

História \&̊ Ensino de História é o sexto livro da coleção História छ̋ Reflexões, da Editora Autêntica, lançado em 2003. Apesar do intervalo entre seu lançamento e a apresentação desta resenha, a obra mantém-se atual por sua qualidade, temática e contribuição à ampla área constituída pela História da Educação, ensino e história do ensino de História. O texto conciso consegue descortinar parte importante da problemática da história do ensino de História no Brasil e trata do tema apresentando o percurso da História como disciplina escolar e sua realização como pesquisa até as últimas décadas do século XX. Por conseguinte, sua leitura é de interesse do amplo público formado por professores e pesquisadores da área.

$\mathrm{O}$ acerto do empreendimento somente seria possível a alguém que conhecesse bem o território a ser desvendado. Thais Nivia de Lima e Fonseca, pesquisadora em História da Educação da UFMG, participa de projetos sobre práticas culturais e educativas em diversos períodos,

\footnotetext{
${ }^{*}$ Resenha recebida em abril de 2006 e aprovada para publicação em junho de 2006.

${ }^{* *}$ Professora das séries iniciais do Ensino Fundamental do Colégio Pedro II; professora-assistente do DCH da FFP/UERJ; doutoranda do PPGE/UFF. E-mail: helenicerocha@uol.com.br.
} 
especialmente o colonial. $\mathrm{O}$ resultado de suas pesquisas contribui para o adensamento do texto com documentos e sua análise. $\mathrm{Na}$ escrita do livro, transita no território interdisciplinar da pesquisa em História e em Educação, cuidando de fontes documentais e preocupando-se com a mediação cultural, seja na escola ou fora dela. A amplitude de sua inserção está indicada no diálogo com um amplo leque de referências bibliográficas.

O livro se divide em quatro capítulos. Já na introdução, Thais anuncia que o ensino de História se insere na problemática da disciplinarização dos conhecimentos, podendo ser abordado a partir de diversos ângulos, o que vai realizar privilegiando a dimensão histórica.

No primeiro capítulo, a autora define a disciplina escolar a partir de referencial amplo e contemporâneo. Esclarece que não irá em busca de "genealogias enganosas" para o ensino de História, endossando advertência de Dominique Julia. ${ }^{1}$ Procura mostrar que, ao longo do século XX, os estudos sobre as disciplinas escolares estiveram demarcados ora pela Sociologia, ora pela História da Educação. Ainda evidencia a importância da noção de transposição didática aplicada à disciplina escolar História a partir de diversos autores, mostrando pontos de convergência e divergência entre eles. A importância deste saber ou conhecimento histórico escolar específico, que não se confunde com o saber acadêmico, vai orientar o percurso da autora ao longo da obra.

$\mathrm{Na}$ breve visão panorâmica acerca dos trabalhos sobre as disciplinas escolares até a década de 1970, há um registro que merece funcionar como alerta para os pesquisadores do ensino de História. É a tendência a enxergar a instituição escolar, as políticas educacionais e o pensamento pedagógico como contextos explicativos privilegiados para os conteúdos e os métodos ensinados nas escolas. A autora diagnostica este movimento vinculado a uma tradição historiográfica que via o Estado como o centro do processo histórico. Sua afirmação nos pode alertar para análises das disciplinas pautadas principalmente ou apenas nas formulações curriculares, em função dos pressupostos pedagógicos ou de políticas públicas.

$\mathrm{Na}$ segunda metade deste capítulo, começa a se desenvolver efetivamente a história do ensino da História. Neste sentido, a obra aprofunda o que é apresentado em

${ }^{1}$ Dominique Julia. "Disciplinas escolares: objetivos, ensino e apropriação", Alice Casemiro Lopes \& Elizabeth Macedo (orgs.), Disciplinas e integração curricular: história e politicas, Rio de Janeiro, DP\&A, 2002, p.37-71. 
algumas outras, como no antológico texto de Elza Nadai ou nos Parâmetros Curriculares Nacionais. ${ }^{3}$ Mostra que, na longa duração, a trajetória da História ensinada nas escolas não corresponde necessariamente à da História como campo do conhecimento, já que a história sagrada e de caráter providencialista ocupou lugar significativo inicialmente nas escolas.

$\mathrm{Na}$ seqüência, o texto incorre em um movimento comum às obras do gênero: atribui à história do ensino de História da França um espaço maior do que possivelmente ocupa, ou seja, generaliza para um todo indistinto, europeu talvez, aquilo que é conhecido para esta história, exaustivamente estudada. Diversas pesquisas históricas, como as da própria autora, começam a evidenciar que, na América colonial portuguesa, as coisas não se passaram tal como François Furet afirma em A Oficina da História ${ }^{4}$ Estas pesquisas indicam que é mais provocador apontar onde há lacunas ou levantar hipóteses relativas ao ensino da História no Brasil Colonial que assumir para este espaço/tempo uma história por extensão à da França moderna.
No segundo capítulo, a obra analisará a coerência entre as tendências apresentadas anteriormente e as pesquisas atuais sobre o ensino de História, concluindo que elas vêm privilegiando um curto recuo temporal. A maior parte dos estudos (em teses, livros e capítulos) se volta para currículos e programas atuais ou recuados no máximo ao período Vargas, e os confronta com a produção historiográfica, estabelecendo um valor relativo para este ensino.

Por conseguinte, a autora avalia que um enfoque histórico sobre o ensino de História é minoritário nos estudos e nas pesquisas e que muitos deles se sustentam fragilmente nas referências teórico-metodológicas contemporâneas, articulando estas referências de maneira vaga ou contraditória. Nesta crítica, é possível inferir uma contribuição da autora às pesquisas que se constroem no limiar da educação e da história. Para além dos problemas de consistência entre os referenciais teórico-metodológicos e a obra apresentada, os textos que tratam da justaposição ou da oposição entre ensino de História e historiografia muitas vezes produzem um efeito

${ }^{2}$ Elza Nadai, "O Ensino de História no Brasil: trajetória e perspectiva", Revista Brasileira de História, v. 13, n. 25/26, São Paulo, 1993.

${ }^{3}$ Brasil, Secretaria de Educação fundamental, Parâmetros Curriculares Nacionais: histórial SEF -Brasília, MEC/SEF, 1998.

${ }^{4}$ François Furet, A oficina da História, Lisboa, Gradiva, s/d. 
secundário: fortalecem um fosso simbólico entre a produção acadêmica e a escolar. Estabelecem, muitas vezes, sem pesquisar no campo da escola e da sala de aula, como ocorrem as práticas, determinando no discurso e no confronto com a historiografia uma prática inventada na teoria e ignorando que elas precisam ser conhecidas de fato e em sua historicidade.

No capítulo III, a pesquisadora vai tratar do ensino de História no Brasil. Nele, o texto vai coincidir em alguns aspectos com a produção existente, como já citado. Entretanto, busca ir além. Procura pincelar os traços de uma educação escolar antes do século XIX, indo em busca do que se aproximaria, àquela época, de um ensino de História. Sua análise de fontes do período pombalino contribui com a história do ensino da História já mais conhecida. O espaço entre os séculos XVIII e XIX apresenta lacunas que não são da obra e sim da pesquisa da área, ainda a ser feita. A autora procura preencher este espaço com dados contextuais e uma análise que interpreta o pensamento social relativo à educação escolar; como exemplo, a relação que estabelece entre o movimento intelectual do século XIX e a escravidão. Este é um dos territórios abertos ao interesse de pesquisas futuras.
A partir dos anos 30 do século XIX, o texto da autora muito contribui para o que está posto em circulação sobre o tema. Seu texto aprofunda a trilha já aberta, mergulhando em fontes diversas e determinando interessantes relações em livros didáticos como em materiais de ensino, textos de apresentação dos mesmos e a legislação pertinente. Quando chega ao $\mathrm{XX}$, no regime militar, o texto consegue elaborar uma alternativa à apresentação de uma época de ouro anterior a este período de nossa história. Entretanto, chega ao limite do problema apontado pela autora no início do livro. Refiro-me à tendência a apresentar as políticas educacionais e o pensamento pedagógico como única origem para os conteúdos e os métodos ensinados nas escolas. Certamente, havia um Estado autoritário, mas ele não era o único centro do processo histórico de que o ensino de História fazia parte.

Assim, àquela época, o currículo e a legislação que interessavam ao regime militar impunham uma visão de sociedade harmoniosa. Com alguma semelhança, no que se refere à ambição de transformação através de instâncias centrais, os PCNs hoje propõem a formação de uma identidade sem muitos conflitos. E o ensino de História acontece na prática, em pla- 
nos que se articulam mais ou menos a ideários ou ideologias presentes em propostas curriculares ou legislações de diferentes tempos. Basta perguntarmos a professores que realizam este ensino, como algumas pesquisas já têm feito, a respeito de pelo menos duas dimensões da realidade social: seu conhecimento sobre os documentos oficiais e o uso ou apropriação que conferem às orientações destes documentos. Não é fato novo a apropriação seletiva de orientações didático-pedagógicas, conforme indicam pesquisas da educação.

Caminhando para o final do século XX, a obra aponta a década de 1980 como o momento de elaboração de propostas curriculares ao nível estadual ou municipal, passando a analisar o programa curricular implantado em Minas Gerais, que seria considerado como síntese de expectativas por um ensino de História democrático e participativo. A autora problematiza como as mudanças trazidas pelo modelo mineiro, concretizadas nos livros e na apropriação de professores, substituiu uma teleologia da história por outra, de orientação marxista. A partir desta mudança, a disciplina escolar História teria acabado sem fato e sem sujeito, com categorias por demais abstratas.
Ao final deste capítulo, somos brindados com uma análise ancorada na História Cultural, contribuição da trajetória de pesquisas da autora. Thais articula a análise de livros e festas cívicas, em torno do tema da Inconfidência Mineira e de seu principal herói no imaginário coletivo, Tiradentes. Em período determinado, a autora mostra como as características do evento e do herói variam e até se deslocam de um pólo ao outro, de acordo com o seu ajuste ao interesse de conformação de certa imagem da nação e de seu povo.

De forma semelhante, no último capítulo, Thais faz um exercício de análise a partir do tema da escravidão entre os séculos XVI e XIX. Agora, seu objetivo "é averiguar as formas de apropriação do conhecimento histórico e suas permanências na memória coletiva, por meio de representações reconhecidas como verdades históricas comprovadas". Iniciando pela revisão historiográfica do final do século XX sobre o tema, a autora avalia como limitada a assimilação desta revisão pelo ensino. Realiza então um exame das fontes em livros didáticos do século relativos ao tema, evidenciando a permanência de concepções nas obras e na memória de ex-estudantes. Conclui pela 
validade de empreendimentos desta natureza em relação a outros temas, períodos e inclusive mídias, assim como registra o efeito de novelas de época na memória de depoentes das pesquisas citadas.

História \&̊ Ensino de História extrapola seu título e seu tamanho, passeando por aspectos do ensino de História e de sua pesquisa. Há uma contribuição adicional presente no conjunto da obra: o uso de temas mineiros em seus exemplos e análises, como a Inconfidência e os documentos de época, de um lado, e a análise da proposta curricular de Minas Gerais, de outro. Tendo em vista a concentração de publicações sobre o tema do ensino no pólo Rio de Janeiro-São Paulo, o surgimento de livros de qualidade a partir de outras regiões ou pólos anuncia um bom recomeço para a escrita da história do ensino de História em nosso país. Anuncia uma história que pode ser reescrita de uma perspectiva plural, portanto, mais complexa. 